Revista Eletrônica do Mestrado em Educação Ambienta1

Programa de Pós-Graduação em Educação Ambiental

\title{
Propostas de diferentes estímulos de educação ambiental voltados para um aluno autista $^{1}$
}

Rozelaine Rubia Bueno D' Almeida ${ }^{2}$ Universidade Federal do Rio Grande do Sul ORCID: https://orcid.org/0000-0002-3939-3978

Bruna Denardin da Silveira ${ }^{3}$ Universidade Federal do Pampa

ORCID: https://orcid.org/0000-0003-4761-1522

Resumo: A educação ambiental, enquanto uma área de estudo, deve abranger os mais diferentes níveis de ensino, tornando-se um espaço para práticas capazes de despertar novos sentimentos, atitudes e valores sobre a natureza. Dessa forma, os alunos com deficiência, também devem ser inseridos neste processo de aprendizagem, independentemente de suas condições pessoais. Portanto, o presente trabalho objetivou promover práticas e estímulos de educação ambiental com um estudante autista. Para o desenvolvimento da pesquisa, utilizou-se de pesquisa bibliográfica para o embasamento do referencial teórico, pesquisa descritiva, abordagem qualitativa e coleta de dados a partir de observação e entrevista não estruturada. Pode-se concluir que é possível promover uma diversificação das práticas pedagógicas articuladas com temas de educação ambiental, representando uma forma de aproximar o aluno a novas experiências com a natureza.

Palavras-chave: Transtorno do Espectro Autista (TEA); Sala de Recursos; Boneco Ecológico.

\section{Propuestas de diferentes estímulos de educación ambiental para un estudiante autista}

Resumen: La educación ambiental, como área de estudio, debe cubrir los más distintos niveles de educación, convirtiéndose en un espacio para prácticas capaces de despertar nuevos sentimientos,

\footnotetext{
${ }^{1}$ Trabalho desenvolvido no curso de especialização em Educação Ambiental (EaD) da UFSM.

${ }^{2}$ Mestre em Integração Latino-Americana pela UFSM (2005). Bacharel em Ciências Econômicas pela Universidade Federal de Santa Maria (2003). Especialista em Educação Ambiental (UAB/UFSM). Graduanda no Curso em Desenvolvimento Rural PLAGEDER/UFRGS. E-mail: prrozelaine@ gmail.com

${ }^{3}$ Doutora em Engenharia Florestal pela Universidade Federal do Paraná (2014). Professora Adjunta da Universidade Federal do Pampa (UNIPAMPA), Campus São Gabriel/RS. E-mail: brunadenardin@ gmail.com
} 
actitudes y valores sobre la naturaleza. Así, los estudiantes con discapacidades, también deben incluirse en este proceso de aprendizaje, independientemente de sus condiciones personales. Por lo tanto, el presente trabajo tuvo como objetivo promover prácticas y estímulos de educación ambiental con un estudiante autista. Para el desarrollo de la investigación, se utilizó la investigación bibliográfica para basar el referencial teórico, la investigación descriptiva, el enfoque cualitativo y la recopilación de datos de la observación y entrevista no estructurada. Se puede concluir que es posible promover una diversificación de las prácticas pedagógicas articuladas con temas de educación ambiental, lo que representa una forma de acercar a los estudiantes a nuevas experiencias con la naturaleza.

Palabras clave: Trastorno del Espectro Autista (TEA); Salón de Recursos; Muñeco Ecológico.

\title{
Proposals of different environmental education stimuli to an autistic student
}

\begin{abstract}
Environmental education, as an area of study, must cover the most different levels of education, becoming a space for practices capable of awakening new feelings, attitudes and values about nature. Thus, students with disabilities should also be included in this learning process, regardless of their personal conditions. Therefore, this study aimed to promote practices and environmental education stimuli with an autistic student. For the development of the research, bibliographic research was used to support the theoretical framework, descriptive research, qualitative approach and data collection from observation and unstructured interview. It can be concluded that it is possible to promote a diversification of pedagogical practices articulated with environmental education themes, representing a way to bring the student closer to new experiences with nature.
\end{abstract}

Keywords: Autistic Spectrum Disorder (ASD); Resource Room; Ecological Doll.

\section{Introdução}

O meio ambiente pode ser percebido de diferentes maneiras, de forma contínua e interdisciplinar, construído pela curiosidade natural que vai se estabelecendo à medida que a criança se desenvolve. Existem muitos conceitos ou habilidades que podem ser apropriados a partir de vivências e experiências pessoais concretizadas de forma prática junto ao ambiente natural, os quais podem possibilitar novas possibilidades de aprendizagem que irão contribuir e estimular o desenvolvimento e as potencialidades individuais que cada ser humano possui.

A Política Nacional de Educação Ambiental estabelece que o tema representa um componente essencial e permanente da Educação Nacional, a qual deve estar presente de forma articulada em todos os níveis e modalidades de ensino formal e não-formal (BRASIL, 1999). Diante disso, percebe-se que as atividades de educação ambiental realizadas na escola devem ser orientadas e desenvolvidas para todos os alunos matriculados, englobando temas pertinentes a realidade da sociedade atual. 
Os alunos das escolas com Atendimento Educacional Especializado (AEE), também estão inseridos no processo de aprendizagem independente das suas condições especiais. A Educação Especial possui como público-alvo as pessoas com deficiência, com transtornos globais do desenvolvimento e com altas habilidades ou superdotação (BRASIL, 2011).

O Transtorno do Espectro Autista (TEA), denominado também por autismo, consiste num tipo de necessidade especial onde o aluno matriculado em classe comum também recebe apoio pedagógico na escola, sendo o atendimento individualizado ou em pequenos grupos. A Lei Brasileira de Inclusão da Pessoa com Deficiência estabelece em seu Art. $4^{\circ}$ que "toda pessoa com deficiência tem direito à igualdade de oportunidades com as demais pessoas e não sofrerá nenhuma espécie de discriminação" (BRASIL, 2015, p. 03).

O estudo da temática proposta é importante em virtude da necessidade de realização de diferentes abordagens da educação inclusiva, a qual possibilita uma enorme variedade de possibilidades junto aos alunos com deficiência.

A educação ambiental representa uma área de conhecimento que deve ser desenvolvida nas diferentes disciplinas do currículo básico, abrangendo os temas mais diversos. Na perspectiva da educação inclusiva, o aluno com necessidades especiais que está integrado no ambiente escolar, também apresenta possibilidades de aprendizagem, considerando as suas características pessoais e suas potencialidades.

O autista necessita de apoio em seu processo de desenvolvimento, sendo estimulado a acreditar no seu potencial para superar suas limitações. Além disso, deve ser respeitado e incluído no meio social em que vive, visto que pode desenvolver talentos diferenciados, podendo contribuir como qualquer outro aluno na sala de aula. A união entre a escola e a família constituem a forma mais importante em busca de uma melhoria de suas condições de vida (ZIRALDO, 2013).

A educação ambiental no âmbito escolar, promotora de saúde e ações voltadas para o cuidado com o meio ambiente deve abranger toda a comunidade escolar. Pelicioni (2005, p. 832), enfatiza que "esse modelo educativo deve alcançar a todos, igualmente, sem exclusão de raça, sexo, deficiência física ou mental, situação econômica ou localização geográfica, procurando reduzir as desigualdades de acesso que existem”.

Diante disso, busca-se responder a seguinte questão problemática: atividades diferenciadas podem ser realizadas no atendimento educacional especializado para estimular a educação ambiental em um aluno autista? 
Assim, o objetivo do presente estudo consistiu em promover práticas e estímulos de educação ambiental com um aluno autista, seguindo os seguintes pressupostos: confeccionar um boneco ecológico para estimular o processo de criação e imaginação; propor formas diferenciadas de estímulos de educação ambiental junto ao meio ambiente; e, estabelecer reflexões sobre a prática e estímulos de educação ambiental realizadas.

\section{Educação Ambiental: concepções teóricas}

A educação ambiental constitui um tema presente nas mais distintas áreas do conhecimento, com diversas possibilidades de abordagens e investigações, a qual vem acompanhada ao longo do tempo pela conscientização da sociedade em torno da defesa do meio ambiente. Conforme Leonardi (2002, p. 391), "a educação ambiental tem sido bastante discutida em vários e diferentes contextos".

Todavia, o conceito de educação ambiental "tem variado ao longo do breve tempo de vida de modalidade pedagógica" (LEONARDI, 2002, p. 394). Além disso, percebe-se que as diferentes definições de educação ambiental variam conforme a formação e experiência profissional de quem as formulou, não se constituindo em uma tarefa fácil atender a tantas diversidades, uma vez que abrange diversas realidades caracterizadas por enorme complexidade.

Portanto, a educação ambiental busca formar e preparar os seres humanos para a reflexão crítica da realidade, mediante uma ação social transformadora, implicando na utilização de subsídios teóricos de diferentes áreas. Enquanto prática democrática, busca a preparação para o exercício da cidadania, seja pela participação ativa individual ou coletiva, levando em consideração aspectos socioeconômicos, políticos e culturais que a influenciam (PELICIONI; PHILIPPI JR, 2005).

Dessa forma, a educação ambiental pode ser compreendida "como uma prática transformadora, comprometida com a formação de cidadãos críticos e co-responsáveis por um desenvolvimento que respeite as mais diferentes formas de vida” (TRISTÃO, 2002, p. 169). Todavia, a mesma tem enfrentado alguns desafios neste início de século, os quais referem-se à existência de uma multiplicidade de saberes, a busca por superar a visão do especialista e a pedagogia das certezas, bem como ultrapassar a lógica da exclusão.

Em outras palavras, a educação ambiental compreende uma área na qual irradiam diferentes concepções teóricas e formas de pensamento, devendo assim, ser superada a visão linear do especialista que impossibilita uma reflexão mais abrangente e articulada 
entre as distintas disciplinas. Além disso, a superação da pedagogia vem de encontro com a necessidade em trazer a reflexão para o ambiente escolar, propondo a superação da lógica da exclusão a partir de uma crítica a realidade social, caracterizada pelas desigualdades sociais e pobreza (TRISTÃO, 2002).

Neste sentido, destaca-se que a educação ambiental "marca uma nova função social da educação, não constitui apenas uma dimensão, nem um eixo transversal, mas é responsável pela transformação da educação como um todo, em busca de uma sociedade sustentável” (LUZZI, 2005, p. 399).

Conforme Legan (2007, p. 11), “a verdadeira educação ambiental só acontece na vivência prática com o ambiente, descobrindo o impacto e o potencial de restauração". Ainda, Freire (1997, p. 43-44) destaca que "é pensando criticamente a prática de hoje ou de ontem que se pode melhorar a próxima prática".

Nota-se, portanto, que a educação ambiental independente da denominação que adquira, ou seja, educação para o desenvolvimento sustentável, educação para o futuro sustentável, educação para as sociedades responsáveis, deve-se encaminhar em busca de um sentido e significado para a existência humana (LUZZI, 2005).

A educação no âmbito escolar esteve durante algum tempo direcionado para as individualidades, não levando em consideração as influências provenientes da realidade socioeconômica, política e cultural as quais os indivíduos estão inseridos (PELICIONI, 2005).

Os problemas ambientais que a população enfrenta, de uma forma geral, repercutem no bem-estar da sociedade e refletem as mudanças e transformações que ocorrem em âmbito globalizado de mundo.

A escola deve propiciar conteúdos direcionados ao meio ambiente, que promovam a reflexão de informações e a formação de valores necessários para mudanças nos estilos de vida. Pelicioni (2005, p. 831) destaca que “o desafio da educação, então, é propiciar bases para compreensão da realidade a fim de poder transformá-la”. Ao mesmo tempo, considera que as áreas da educação, saúde e meio ambiente devem fortalecer-se no contexto do ensino formal e informal, atuando como uma importante força para a promoção dessas ideias.

Do ponto de vista formal, a educação ambiental é aquela exercida no âmbito escolar, representando um assunto relativamente novo, tanto no que se refere a política pública como uma preocupação de educadores, famílias, intelectuais e profissionais de distintas áreas do saber (LEONARDI, 2002). 


\section{Educação especial e inclusiva de pessoas em condições especiais}

A educação especial representa uma grande área do conhecimento, segundo o Art. 58 da Lei $n^{\circ}$ 9.394/96 é uma modalidade de educação escolar que inclui um serviço de apoio especializado, dadas as condições específicas de educandos com deficiência, transtornos globais do desenvolvimento e altas habilidades ou superdotação, sendo realizada preferencialmente na rede regular de ensino (BRASIL, 1996).

A Política Nacional de Educação Especial na Perspectiva da Educação inclusiva surge como uma forma de fortalecer o movimento de inclusão, à medida que define o público-alvo da Educação Especial e suas diretrizes específicas. Assim, tem-se definidas as atividades desenvolvidas no Atendimento Educacional Especializado (AEE), as quais complementam ou suplementam a formação dos estudantes, tendo em vista as suas necessidades educacionais especiais (BRASIL, 2008).

A Política Nacional de Educação Especial na Perspectiva da Educação Inclusiva objetiva assegurar a inclusão escolar e garantir o acesso ao ensino regular, a participação, aprendizagem e continuidade de estudos para o público alvo da Educação Especial, desde a educação infantil até a educação superior. Além disso, destaca a formação necessária do professor que atua no atendimento educacional especializado e as adequações necessárias em termos de estrutura dos estabelecimentos de ensino, a acessibilidade, bem como a participação da família e da comunidade (BRASIL, 2008).

O autismo é uma alteração no desenvolvimento caracterizada por mudanças no processo de relacionamento com outras pessoas, comunicação e imaginação, as quais podem ser percebidas antes dos três anos de idade. Conforme Mello (2007, p. 17), "as causas do autismo são desconhecidas. Acredita-se que a origem do autismo esteja em anormalidades em alguma parte do cérebro ainda não definida de forma conclusiva e, provavelmente, de origem genética". Além disso, julga-se ainda que pode existir uma relação da doença com fatos ocorridos durante a gestação e parto.

De forma conjunta ou isolada, os autistas podem apresentar as seguintes características:

- apresentam isolamento mental, daí o nome autismo. Esse isolamento despreza, exclui e ignora o que vem do mundo externo; - possuem uma insistência obsessiva na repetição, com movimentos e barulhos repetitivos e estereotipados; - adotam elaborados rituais e rotinas; - têm fixações e fascinações altamente direcionadas e intensas; - apresentam escassez de expressões faciais e gestos; - não olham diretamente para as pessoas; - têm uma utilização anormal da linguagem; - apresentam boas 
relações com objetos; - apresentam ansiedade excessiva; - não adquirem a fala ou perdem a anteriormente adquirida (MINISTÉRIO DA SAÚDE, 2000 , p. 8 , grifos no original).

O diagnóstico do autismo é difícil, sendo na maior parte dos casos “"[...] percebidos na escola (ainda no pré-escolar) pelos professores que, no convívio cotidiano e grupal, podem observar a impossibilidade destas crianças de se relacionar, seja com outras crianças, seja com os próprios professores" (MINISTÉRIO DA SAÚDE, 2000, p. 10).

\section{Materiais e métodos}

\section{Considerações sobre o contexto do local de estudo}

O referido trabalho foi realizado na Escola Estadual de Ensino Fundamental Luiz Fogliatto em Ijuí, Rio Grande do Sul, a qual atende crianças do $1^{\circ}$ ao $5^{\circ}$ ano dos anos iniciais, considerando a Matriz Curricular Estadual do Tempo Integral, e alunos do $6^{\circ}$ ao $9^{\circ}$ ano dos anos finais, no turno da manhã.

Os estudantes em condições especiais são matriculados nas turmas regulares, sendo atendidos na sala de recursos no turno inverso à escolarização, ou seja, possuem apoio pedagógico na escola. No ano de 2018 a escola possuía um total de 220 alunos matriculados, sendo 14 alunos com necessidades especiais, totalizando seis alunos nos anos iniciais e oito alunos nos anos finais. Destes, nove alunos apresentam deficiência intelectual, dois alunos possuem deficiência múltipla e três alunos são autistas.

A escola possui uma Sala de Recursos Multifuncional, onde se realiza o Atendimento Educacional Especializado (AEE) para os alunos com deficiência, transtornos globais do desenvolvimento, altas habilidades e superdotação.

\section{Plano de pesquisa e coleta de dados}

As práticas e estímulos de educação ambiental foram realizadas com o único aluno dos anos iniciais que possui um quadro clínico compatível de autismo infantil, sendo que o mesmo possuía, em 2018, sete anos de idade e encontrava-se devidamente matriculado no $2^{\circ}$ ano. O referido aluno permanecia na escola no horário das $7 \mathrm{~h} 30 \mathrm{~min}$ às $15 \mathrm{~h} 45 \mathrm{~min}$, com exceção de segunda-feira, onde o horário das aulas para os anos iniciais tem início às 9 h00min. 
Do ponto de vista dos procedimentos de pesquisa, o trabalho é classificado em bibliográfico e descritivo. A pesquisa bibliográfica "busca conhecer e analisar as contribuições culturais ou científicas do passado existentes sobre um determinado assunto, tema ou problema" (CERVO; BERVIAN, 1996, p. 48).

Utilizou-se também de pesquisa descritiva para registrar e analisar momentos e situações vivenciadas. Em relação à pesquisa descritiva, considera-se que a mesma procura conhecer diferentes situações e relações que se desenvolvem na vida de um indivíduo isoladamente ou de um grupo ou comunidade (CERVO; BERVIAN, 1996).

Como instrumento para a coleta das informações, a técnica utilizada baseou-se em entrevista não estruturada junto à professora de educação especial que fez o atendimento na sala de recursos e que realizou a prática de confecção do boneco ecológico. Da mesma forma, foi realizada entrevista não estruturada com a outra professora/monitora que fez o acompanhamento do estudante no turno da tarde e que auxiliou nas demais possibilidades de estímulos no ambiente escolar. Segundo a Lei n. 12.764 de dezembro de 2012, art. $3^{\circ}$ parágrafo único "em casos de comprovada necessidade, a pessoa com transtorno do espectro autista incluída nas classes comuns de ensino regular, nos termos do inciso IV do art. $2^{\circ}$, terá direito a acompanhante especializado" (BRASIL, 2012, p. 02).

Conforme Gil (2005), a entrevista objetiva obter os dados de interesse para o estudo, representando uma forma de interação social, sendo utilizada na realização de pesquisas, diagnósticos e orientação.

As entrevistas com as professoras ocorreram de forma espontânea e sem um roteiro prévio, tiveram como objetivo coletar informações que pudessem retratar de uma maneira mais detalhada as reações do aluno, visto que a presença de uma pessoa diferente do habitual pode atrapalhar e influenciar no comportamento do educando. Dessa forma, as entrevistas foram realizadas posteriormente à realização da prática e estímulos, sem a presença do aluno.

O planejamento de confecção do boneco ecológico foi realizado pela professora da sala de recursos como uma prática pedagógica diferenciada, condizente com o ritmo e as potencialidades do estudante.

Já as formas diferenciadas de estímulos de educação ambiental no atendimento educacional especializado foram propostas como novas possibilidades de experiências e aprendizagens, uma vez que são variadas as formas de terapias e tratamentos voltados para o autista, dentre elas destacam-se aquelas voltadas para a manipulação de objetos, brincadeiras e estimulação das habilidades. 
Depois de realizada, de forma breve, a observação da prática de confecção do boneco ecológico e os respectivos estímulos de educação ambiental no espaço escolar, foi feita a descrição das mesmas. Na sequência, buscou-se com as entrevistas acrescentar informações relativas aos gestos, comportamentos e reações do aluno quando da realização das atividades, realizando-se assim, a complementação das informações e posteriormente a análise das mesmas.

\section{Resultados e discussão}

\section{Confecção de um boneco ecológico por um aluno autista}

Em um primeiro momento foi proposta a literatura infantil "O cabelo de Lelê" de autoria de Valéria Belém (2007), com o objetivo de criar um boneco ecológico e estimular a criação e imaginação do educando. Depois de realizada a leitura do livro, por parte da professora de Educação Especial, foi entregue ao aluno um desenho já pronto com a imagem de uma cabeça com cabelos, sendo ofertados diferentes materiais alternativos composto de barbante e cola colorida, glitter, lantejoulas, tesoura e canudinhos, com o intuito de fazer um auto-retrato do personagem da história.

$\mathrm{Na}$ tarefa realizada, observou-se o envolvimento do aluno, respeitando suas potencialidades durante o processo de criação da figura, sendo que o exercício teve como objetivo o desenvolvimento da psicomotricidade. Nater (2016) salienta que o autista possui um comprometimento nos aspectos relacionados à linguagem falada, assim como características corporais específicas. Porém, no presente trabalho, percebeu-se o interesse do estudante, que desenvolveu a tarefa com êxito.

Assim, esta atividade permitiu auxiliar no processo de alfabetização do aluno, desenvolvimento intelectual, no contato físico e manuseio com diferentes objetos. É importante salientar que o educando ainda não era alfabetizado e possuía dificuldades relacionadas às habilidades com recorte e colagem. Conforme Belisário Júnior e Cunha (2010), a criança autista possui um interesse por rotinas, podendo ignorar outras crianças, assim como, apresentar manifestações de inflexibilidade no ambiente escolar. Porém, o estudante não se mostrou resistente e pareceu apreciar a tarefa.

Na sequência, a prática prosseguiu no espaço externo da sala de aula, ou seja, ao ar livre, buscando-se constituir um elo natural entre o aluno e os materiais que seriam utilizados e com a natureza de forma simultânea. Neste segundo momento, foi 
confeccionado um boneco ecológico visando oportunizar de uma forma concreta a percepção tátil de diferentes materiais e, estimular outras habilidades, promovendo estímulos voltados a educação ambiental.

Inicialmente, foram apresentados ao aluno os diferentes elementos que seriam utilizados para a confecção do Boneco Ecológico, incluindo uma meia fina, o solo, a serragem, a água, os grãos de aveia, as tintas e os pincéis. Neste instante, buscou-se demonstrar que aquele solo representa a base da vida de todos os seres vivos e que o mesmo realiza tarefas vitais no meio ambiente.

Neste sentido, estabeleceu-se o contato físico das mãos do estudante com o solo, a serragem e demais elementos da natureza, sabendo-se que o mesmo possui dificuldades em tocar e sujar as mãos. Neste cenário, foi realizada a aproximação do aluno com os elementos apresentados, não ocorrendo uma recusa por parte dele para a realização da atividade, visto que representava uma situação nova e diferente da sua rotina habitual na escola, contrariando os comentários de Brande e Zanfelice (2012) que afirmam que são frequentes os relatos acerca das dificuldades apresentadas pelos alunos autistas quanto às mudanças de rotina e socialização.

O processo de criação do boneco continuou à medida que o procedimento foi sendo desenvolvido. Dessa forma, tem-se a fase de criação do boneco ecológico por parte do aluno com o auxílio da professora. Primeiramente, colocou-se no interior da meia fina a mistura da serragem com os elementos provenientes do solo, por fim, foram dispostos os grãos de aveia no composto. Com isso, buscou-se criar uma conexão da criança com o meio, uma vez que a mesma pode vivenciar de forma saudável uma nova experiência de aprendizagem infantil.

Depois de terminado o enchimento da meia, o processo de modelagem do bonequinho iniciou. Esta etapa foi realizada pelo aluno de maneira orientada e de acordo com o seu gosto, onde buscou-se deixar o aluno livre para estabelecer o contato com a forma criada.

Finalizada a etapa de modelagem, iniciou-se a caracterização externa do boneco, considerando o aspecto lúdico que o envolve, a estimulação do processo criativo, a percepção tátil, atenção, coordenação motora e consciência ambiental. Mello (2007) considera que a criança autista apresenta dificuldade no uso da imaginação e em processos criativos, questões percebidas durante as brincadeiras e no contato com os objetos e brinquedos. Para tanto, utilizou-se de tintas e pincéis para dar o formato de rosto ao boneco. 
Após o término do mesmo, buscou-se demonstrar a importância da água na vida das plantas e a noção de responsabilidade. Segundo Machado (2003), o crescimento acelerado da população e, consequentemente, o desenvolvimento industrial e tecnológico tem comprometido ou colocado em risco as poucas fontes disponíveis de água doce existentes no planeta. $\mathrm{O}$ mesmo autor ainda destaca que a poluição dos mananciais, o desmatamento, o assoreamento dos rios, o uso incorreto de irrigação e a impermeabilização do solo, entre tantas outras ações humanas, são responsáveis pela escassez e contaminação da água.

Por isso, quando o professor precisa trabalhar com um tema tão complexo, como a água, torna-se necessário uma maior capacidade deste profissional de explorar o ambiente de forma mais contextualizada (BACCI; PATACA, 2008). Desta forma, ficou combinado que o aluno seria o responsável por molhar todos os dias, durante uma semana, o boneco para o crescimento das sementinhas, e assim, dar origem aos cabelinhos do mesmo. Vale ressaltar que a água é uma necessidade básica para todas as formas de vida e isso foi abordado durante toda a realização da atividade. Assim, o aluno pode perceber as características físicas da água, ou seja, que a mesma é incolor e inodora. Buscou-se ainda, despertar o cuidado no uso da mesma.

Para o momento da realização da rega, foi disposto um pouco de água em uma tigela pequena de formato arredondado. Cabe salientar que o educando teve bastante resistência em colocar a mão no recipiente com água, sendo que várias tentativas tiveram que ser feitas para que então fosse concretizada a ação. No entanto, o contato com a água da torneira pelo educando é normal, visto que o mesmo já está habituado a utilizá-la. Podese afirmar que tal resistência ocorre pelo fato da situação apresentar-se como nova, ou seja, diferente da sua rotina diária.

Ao final da tarefa concluiu-se que a atividade foi significativa para o aluno, visto que o mesmo prosseguiu molhando todos os dias o seu boneco, inclusive levando o mesmo para a sua casa. Como resultado, apenas duas sementes germinaram, correspondendo a "dois fios de cabelo" do boneco. Este fato pode ser decorrente do excesso de água ou de sementes dispostas pelo educando durante a confecção do mesmo. Isso mostra que experiências como essas devem ser auxiliadas por profissionais da área, indicando a importância da formação de professores do ensino fundamental e médio na área ambiental, pois através de sua capacitação o tema meio ambiente pode ser melhor abordado em sala de aula, obtendo-se sucesso nessas práticas.

Neste contexto, considera-se importante estabelecer situações diferentes do habitual ao educando. Rosa; Matsukurab; Squassonic (2019) destacam sobre a importância do 
planejamento individualizado das pessoas com TEA e uma atenção integrada, envolvendo aspectos do campo pedagógico, social, terapêutico, recreativo e cultural, tendo em vista um desenvolvimento integral desses sujeitos.

\section{Outras possibilidades de estímulos no contexto do ambiente escolar}

Buscou-se envolver o aluno com outros estímulos de natureza sensorial, com o objetivo de proporcionar uma nova forma de aprendizagem com os elementos do meio ambiente encontrados no espaço da escola.

O pátio da escola é constituído de uma área livre com uma diversidade de possibilidades que podem ser aproveitadas como forma de promover o interesse pela aprendizagem, contendo várias árvores, areia, flores, frutos, pássaros e plantas em geral. Com isso, o estudante pode estabelecer contato físico com as árvores como uma forma de proporcionar a percepção da cor, altura, textura e sua forma.

As flores e diferentes plantas adicionam um aspecto colorido e agradável ao ambiente, possuindo características variadas que podem ser percebidas pelo contato físico e pela percepção visual. A partir do relato da professora, o educando mencionou ter percebido a cor vermelha da flor e sua textura felpuda e macia, sendo que ele ainda mencionou que a mesma pareceria ser cheirosa.

O espaço da escola não possui uma horta, onde pudesse ser feito uma atividade voltada para a colheita e consumo direto de alimentos. Dessa forma, foi possível propor ao aluno colher e, posteriormente, consumir os frutos de uma amoreira, visto que na escola existem duas árvores de amoras com uma enorme quantidade de frutos já maduros.

Respeitando as dificuldades e limitações do estudante, o processo de observação do local por parte da criança foi estabelecido, assim como a retirada de poucas amoras da árvore e o seu posterior consumo. Conforme Freire (1997), o ato de ensinar exige aceitar situações novas que possam surgir durante o processo de aprendizagem, assim como rejeitar as mais variadas formas de discriminação.

Assim, conforme a professora/monitora o aluno considerou difícil colher as amoras, em virtude da altura das mesmas, mas pareceu apreciar o fruto, pois os consumiu no local, além disso teve a percepção das cores roxa e verde. Cabe salientar que, o educando já havia realizado em outros momentos esta mesma atividade na companhia da profissional da escola. 
Esta experiência buscou possibilitar ainda uma percepção visual para o ambiente como um todo, bem como para a árvore e os frutos de forma específica. Para Mattos e Nuernberg (2011), os processos inclusivos são importantes para ampliar as possibilidades das pessoas com deficiência, contribuindo para o seu desenvolvimento pessoal e social.

A atividade foi proposta de forma estimulante, prática e sensível, onde o estudante explorou o local de forma livre e espontânea, sendo essa alternativa diferenciada de experiência com a natureza. Legan (2007) e Leonardi (2005) apontam para as atividades práticas de educação ambiental que podem ser realizadas ao ar livre, as quais oferecem o contato direto com a natureza, podendo ser explorada de diferentes formas e em qualquer idade ou nível escolar.

Neste sentido, foi sugerido também para o aluno retirar os calçados e caminhar pela grama, folhas secas e na quadra de areia. Segundo relato da professora/monitora, ao andar nas folhas secas o aluno notou o barulho ao caminhar sobre elas. Já na grama comentou sobre o formato da mesma, sentiu coceira nos pés e percebeu a presença de formigas no local. Durante o tempo que permaneceu na areia, constatou a consistência macia, fria e a sujeira da mesma, considerando bom caminhar descalço tanto na areia, como sobre as folhas secas.

Portanto, a educação ambiental se configura como uma forma de preparar os cidadãos para a reflexão crítica da realidade, a fim de tornar viável o desenvolvimento integral dos seres humanos (PELICIONI; PHILIPPI JR, 2005).

Assim, pode-se dizer que a educação ambiental surge com o objetivo de despertar a consciência ecológica em cada ser humano, oportunizando conhecimentos que possam permitir uma mudança de comportamento frente as questões relativas ao cuidado e manutenção dos recursos naturais existentes. Além disso, a educação ambiental corresponde a um processo participativo, onde os indivíduos assumem o papel de agente transformador, envolvendo-se ativamente nas discussões acerca dos problemas ambientais e na tomada de decisões, desenvolvendo habilidades e atitudes éticas condizentes ao exercício da cidadania (CASTRO; CANHEDO JR, 2005).

\section{Considerações Finais}

A tarefa de confecção do boneco ecológico mostrou-se significativa e importante para o aluno, uma vez que o mesmo estabeleceu o hábito de molhar o boneco após a sua finalização, despertando o cuidado e a responsabilidade. Durante a atividade, foi possível 
constatar as atitudes de respeito ao aluno com deficiência, visto que durante toda a atividade buscou-se respeitar as suas limitações. Além disso, destaca-se a importância do apoio as práticas pedagógicas de atenção às diferenças, as quais visam possibilitar novas possibilidades e experiências de aprendizagem.

O contato com a natureza foi sugerido como uma forma diferenciada de estabelecer estímulos de educação ambiental para um aluno autista, buscando-se aproveitar dos recursos existentes no espaço da escola. A partir do contato com as árvores, flores, frutos e com o solo pode-se constatar que o aluno pode perceber detalhes dos diferentes ambientes no qual ele entrou em contato, ou seja, teve a percepção das características físicas da árvore, flores e frutos, bem como do aspecto do solo enquanto caminhava descalço, demonstrando inclusive preferências pessoais.

Assim sendo, torna-se necessário estabelecer mudanças de concepções em relação aos alunos com deficiência, considerando as suas necessidades e as suas potencialidades individuais. Por outro lado, a partir da criatividade é possível promover uma diversificação das práticas pedagógicas articuladas com temas de educação ambiental, representando uma forma de aproximar o aluno a novas experiências com a natureza, uma vez que podem ser estabelecidos com facilidade no contexto escolar. O contato com o meio ambiente possibilita liberdade para o aluno se expressar de uma forma diferenciada do habitual, oportunizando condições para superar as suas dificuldades.

Diante do referido estudo, recomenda-se realizar o mesmo trabalho com outros alunos com necessidades especiais, visando estabelecer outras análises e experiências. Por outro lado, poderiam ser acrescentadas outras formas de estímulo junto ao meio ambiente, sendo estas oferecidas durante viagens e passeios realizados pela escola.

\section{Referências}

BACCI, Denise de La Corte; PATACA, Ermelinda Moutinho. Educação para a água. Estudos Avançados. v. 22, n. 63, p. 211-226, 2008. Disponível em: https://www.scielo.br/pdf/ea/v22n63/v22n63a14.pdf. Acesso em: 13 mar. 2020.

BELÉM, Valéria. O cabelo de Lelê. São Paulo: Companhia Editora Nacional, 2007.

BELISÁRIO JÚNIOR, José Ferreira; CUNHA, Patrícia. A Educação Especial na Perspectiva da Inclusão Escolar: transtornos globais do desenvolvimento. Brasília: Universidade Federal do Ceará, 2010. Disponível em: https://central3.to.gov.br/arquivo/299634/. Acesso em: 10 out. 2019. 
BRANDE, Carla Andréa; ZANFELICE, Camila Cilene. A inclusão escolar de um aluno com autismo: diferentes tempos de escuta, intervenção e aprendizagens. Revista Educação Especial. v. 25, n. 42, p. 43-56, jan./abr. 2012. Disponível em:

https://periodicos.ufsm.br/educacaoespecial/article/view/3350. Acesso em: 10 out. 2019.

BRASIL. Lei no 9.394 de 20 de dezembro de 1996. Lei de Diretrizes e Bases para a Educação. Brasília: Senado Federal, 1996.

BRASIL. Lei no . 9.795, de 27 de abril de 1999. Dispõe sobre a Educação Ambiental, institui a Política Nacional de Educação Ambiental e dá outras providências. Brasília: Senado Federal, 1999. Disponível em: http://www.planalto.gov.br/ccivil_03/leis/19795.htm. Acesso em: 21 nov. 2018.

BRASIL. Política Nacional de Educação Especial na Perspectiva da Educação Inclusiva. Brasília: MEC/SECADI, 2008. Disponível em: http://portal.mec.gov.br/index.php?option=com_docman\&view=download\&alias=16690politica-nacional-de-educacao-especial-na-perspectiva-da-educacao-inclusiva05122014\&Itemid=30192. Acesso em: 13 nov. 2018.

BRASIL. Decreto $\mathbf{n}^{0}$ 7.611, de 17 de novembro de 2011. Dispõe sobre a educação especial, o atendimento educacional especializado e dá outras providências. Disponível em: http://www.planalto.gov.br/ccivil_03/_Ato2011-2014/2011/Decreto/D7611.htm. Acesso em: 14 nov. 2011.

BRASIL. Lei $\mathbf{n}^{\mathbf{0}}$. 12.764, de 27 de dezembro de 2012. Institui a Política Nacional de Proteção dos Direitos da Pessoa com Transtorno do Espectro Autista. Brasília: Senado Federal, 2012. Disponível em: http://www.planalto.gov.br/ccivil_03/_ato20112014/2012/lei/112764.htm. Acesso em: 20 nov. 2018.

BRASIL. Lei no. 13.146, de 06 de julho de 2015. Institui a Lei Brasileira de Inclusão da Pessoa com Deficiência (Estatuto da Pessoa com Deficiência). Brasília: Senado Federal, 2015. Disponível em: http://www.punf.uff.br/inclusao/images/leis/lei_13146.pdf. Acesso em: 22 out. 2018.

CASTRO, Mary Lobas de; CANHEDO JR, Sidnei Garcia. Educação Ambiental como instrumento de participação. In: PHILIPPI JR, Arlindo; PELICIONI, Maria Cecília Focesi (ed.). Educação ambiental e sustentabilidade. Barueri: Manole, 2005.

CERVO, Amado Luiz; BERVIAN, Pedro Alcino. Metodologia científica. São Paulo: Prentice Hall, 1996.

FREIRE, Paulo. Pedagogia da Autonomia: Saberes necessários à Prática Educativa. São Paulo: Paz e Terra, 1997.

GIL, Antonio Carlos. Métodos e Técnicas de Pesquisa em Educação Ambiental. In: PHILIPPI JR, Arlindo; PELICIONI, Maria Cecília Focesi (ed.). Educação ambiental e sustentabilidade. Barueri: Manole, 2005.

MATTOS, Laura Kemp de; NUERNBERG, Adriano Henrique. Reflexões sobre a Inclusão Escolar de uma Criança com Diagnóstico de Autismo na Educação Infantil. Revista 
Educação Especial, v. 24, p. 113-127, jan./abr. 2011. Disponível em:

https://periodicos.ufsm.br/educacaoespecial/article/view/1989/1720. Acesso em: 10 out. 2019.

LEGAN, Lucia. A escola sustentável: ecoalfabetizando pelo ambiente. São Paulo: Imprensa Oficial do Estado de São Paulo; Pirenópolis: Ecocentro IPEC, 2007.

LEONARDI, Maria Lúcia Azevedo. A educação ambiental como um dos instrumentos de superação da insustentabilidade da sociedade atual. In: CAVALCANTI, Clóvis (org.). Meio ambiente, desenvolvimento sustentável e políticas públicas. 4 ed. São Paulo: Cortez, 2002.

LUZZI, Daniel. Educação ambiental: pedagogia, política e sociedade. In: PHILIPPI JR, Arlindo; PELICIONI, Maria Cecília Focesi (ed.). Educação ambiental e sustentabilidade. Barueri, SP: Manole, 2005.

MACHADO, Carlos José Saldanha. Recursos hídricos e cidadania no Brasil: limites, alternativas e desafios. Ambiente \& Sociedade [online]. v. 6, n. 2, 2003. Disponível em: https://www.scielo.br/scielo.php?script=sci_arttext\&pid=S1414753X2003000300008\&lng=en\&nrm=iso\&tlng=pt\#nt02a. Acesso em: 13 mar. 2020.

MELLO, Ana Maria S. Ros de. Autismo: guia prático. 6. ed. São Paulo: AMA; Brasília: CORDE, 2007. Disponível em:

http://www.autismo.org.br/site/images/Downloads/7guia\%20pratico.pdf. Acesso em: 13 nov. 2018.

MINISTÉRIO DA SAÚDE. Autismo: orientação para os pais. Casa do Autista. Brasília: Ministério da Saúde, 2000. Disponível em:

https://bvsms.saude.gov.br/bvs/publicacoes/cd03_14.pdf. Acesso em: 13 nov. 2018.

NATER, Elizabeth. Transtornos Globais do Desenvolvimento. Material didático da disciplina de Transtornos Globais do Desenvolvimento - Faculdade São Braz (FSB), Editora São Braz, Curitiba, 2016.

PELICIONI, Maria Cecília Focesi. Educação ambiental para uma escola saudável. In: PHILIPPI JR, Arlindo; PELICIONI, Maria Cecília Focesi (ed.). Educação ambiental e sustentabilidade. Barueri, SP: Manole, 2005.

PELICIONI, Maria Cecília Focesi; PHILIPPI JR, Arlindo. Bases políticas, conceituais, filosóficas e ideológicas da educação ambiental. In: PHILIPPI JR, Arlindo; PELICIONI, Maria Cecília Focesi (ed.). Educação ambiental e sustentabilidade. Barueri/SP: Manole, 2005.

ROSA, Fernanda Duarte; MATSUKURA, Thelma Simões; SQUASSONI, Carolina Elisabeth. Schooling of people with Autism Spectrum Disorder (ASD) in adulthood: reports and perspectives of parents and caregivers of adults with ASD. Cadernos Brasileiros de Terapia Ocupacional. v. 27, n. 2, p. 302-316, 2019. Disponível em: https://www.scielo.br/scielo.php?pid=S252689102019005005102\&script=sci_arttext\&tlng=en. Acesso em: 17 jan. 2020. 
TRISTÃO, Martha. As dimensões e os desafios da educação ambiental na sociedade do conhecimento. In: RUSCHEINSKY, Aloísio (Org.). Educação ambiental: abordagens múltiplas. Porto Alegre: Artmed, 2002.

ZIRALDO. Autismo: uma realidade. 2013. Disponível em:

http://www.mpsp.mp.br/portal/page/portal/cao_civel/cartilha-ziraldo-autismo-umarealidade.pdf. Acesso em: 07 out. 2018.

Submetido em: 02-06-2020.

Publicado em: 18-12-2020. 